
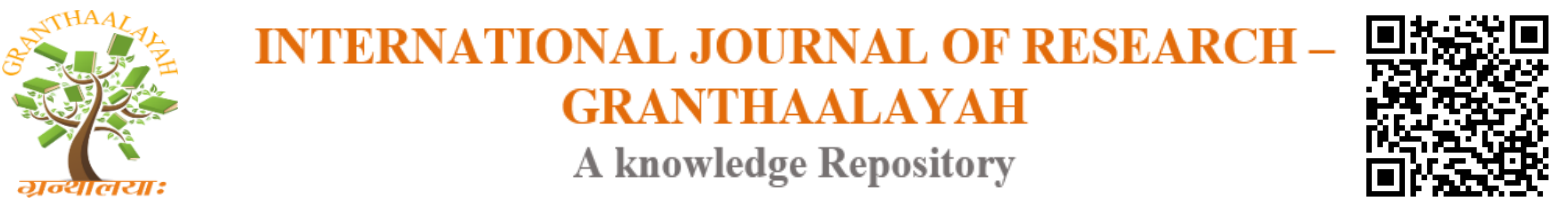

Science

\title{
ACTIVE POWER LOSS REDUCTION BY FLOWER POLLINATION
} ALGORITHM

\author{
Dr.K.Lenin *1 \\ ${ }^{* 1}$ Professor, Department of EEE, Prasad V.Potluri Siddhartha Institute of Technology, Kanuru, \\ Vijayawada, Andhra Pradesh -520007, India
}

\begin{abstract}
This paper presents Flower Pollination (FP) algorithm for solving the optimal reactive power problem. Minimization of real power loss is taken as key intent. Flower pollination algorithm is a new nature-inspired algorithm, based on the characteristics of flowering plants. The biological evolution point of view, the objective of the flower pollination is the survival of the fittest and the optimal reproduction of plants in terms of numbers as well as the largely fittest. In order to evaluate the performance of the proposed Flower Pollination (FP) algorithm, it has been tested on IEEE 57 bus system and compared to other standard reported algorithms. Simulation results show that FP algorithm is better than other algorithms in reducing the real power loss and voltage profiles are within the limits.
\end{abstract}

Keywords: Flower Pollination; Optimization; Optimal Reactive Power; Transmission Loss.

Cite This Article: Dr.K.Lenin. (2017). "ACTIVE POWER LOSS REDUCTION BY FLOWER POLLINATION ALGORITHM.” International Journal of Research - Granthaalayah, 5(12), 223-231. https://doi.org/10.29121/granthaalayah.v5.112.2017.497.

\section{Introduction}

Optimal reactive power problem plays most important role in the stability of power system operation and control. In this paper the main aspect is to diminish the real power loss and to keep the voltage variables within the limits. Previously many mathematical techniques like gradient method, Newton method, linear programming [4-7] has been utilized to solve the optimal reactive power dispatch problem and those methods have many difficulties in handling inequality constraints. Voltage stability and voltage collapse play an imperative role in power system planning and operation [8]. Recently Evolutionary algorithms like genetic algorithm have been already utilized to solve the reactive power flow problem [9,10].In [11-20] Genetic algorithm, Hybrid differential evolution algorithm, Biogeography Based algorithm, fuzzy based methodology, improved evolutionary programming has been used to solve optimal reactive power flow problem and all the algorithm successfully handled the reactive power problem. The Artificial Bee Colony (ABC) algorithm was introduced by Karaboga [21] as a technical report, and then its performance was measured using benchmark optimization functions [22-33]. This 
paper presents Flower Pollination (FP) algorithm for solving the optimal reactive power problem. Minimization of real power loss is taken as key intent. Flowering plant [34-37] has been evolving for at least more than million of million years. It is approximate that there are over asection of a million types of flowering plants in Nature and that about $90 \%$ of all plant species are flowering species. The performance of Flower Pollination (FP) algorithm has been evaluated in standard IEEE 57 bus test system and the simulation results shows that our proposed method outperforms all approaches investigated in this paper.

\section{Objective Function}

\subsection{Active Power Loss}

The objective of the reactive power dispatch problem is to minimize the active power loss and can be defined in equations as follows:

$\mathrm{F}=\mathrm{PL}=\sum_{\mathrm{k} \in \mathrm{Nbr}} \mathrm{g}_{\mathrm{k}}\left(\mathrm{V}_{\mathrm{i}}^{2}+\mathrm{V}_{\mathrm{j}}^{2}-2 \mathrm{~V}_{\mathrm{i}} \mathrm{V}_{\mathrm{j}} \cos \theta_{\mathrm{ij}}\right)$

Where $g_{k}$ : is the conductance of branch between nodes $i$ and $j$, Nbr: is the total number of transmission lines in power systems.

\subsection{Voltage Profile Improvement}

To minimize the voltage deviation in PQ buses, the objective function can be written as:

$\mathrm{F}=\mathrm{PL}+\omega_{\mathrm{v}} \times \mathrm{VD}$

Where $\omega_{\mathrm{v}}$ : is a weighting factor of voltage deviation.

VD is the voltage deviation given by:

$$
\mathrm{VD}=\sum_{\mathrm{i}=1}^{\mathrm{Npq}}\left|\mathrm{V}_{\mathrm{i}}-1\right|
$$

\subsection{Equality Constraint}

The equality constraint of the problem is indicated by the power balance equation as follows:

$$
P_{G}=P_{D}+P_{L}
$$

Where the total power generation PG has to cover the total power demand PD and the power losses PL.

\subsection{Inequality Constraints}

The inequality constraint implies the limits on components in the power system in addition to the limits created to make sure system security. Upper and lower bounds on the active power of slack bus, and reactive power of generators are written as follows: 


$$
\begin{gathered}
\mathrm{P}_{\text {gslack }}^{\min } \leq \mathrm{P}_{\text {gslack }} \leq \mathrm{P}_{\text {gslack }}^{\max } \\
\mathrm{Q}_{\mathrm{gi}}^{\min } \leq \mathrm{Q}_{\mathrm{gi}} \leq \mathrm{Q}_{\mathrm{gi}}^{\max }, \mathrm{i} \in \mathrm{N}_{\mathrm{g}}
\end{gathered}
$$

Upper and lower bounds on the bus voltage magnitudes:

$$
V_{i}^{\min } \leq V_{i} \leq V_{i}^{\max }, i \in N
$$

Upper and lower bounds on the transformers tap ratios:

$$
\mathrm{T}_{\mathrm{i}}^{\min } \leq \mathrm{T}_{\mathrm{i}} \leq \mathrm{T}_{\mathrm{i}}^{\max }, \mathrm{i} \in \mathrm{N}_{\mathrm{T}}
$$

Upper and lower bounds on the compensators

$$
\mathrm{Q}_{\mathrm{c}}^{\min } \leq \mathrm{Q}_{\mathrm{c}} \leq \mathrm{Q}_{\mathrm{C}}^{\max }, \mathrm{i} \in \mathrm{N}_{\mathrm{C}}
$$

Where $\mathrm{N}$ is the total number of buses, NT is the total number of Transformers; Nc is the total number of shunt reactive compensators.

\section{Flower Pollination Algorithm}

The flower reproduction is ultimately through pollination. Flower pollination is connected with the transfer of pollen, and such transfer of pollen is related with pollinators such as insects, birds, animals etc. some type of flowers depend only on specific type of insects or birds for successful pollination. Two main forms of pollination are A-biotic and biotic pollination. $90 \%$ of flowering plants are belonging to biotic pollination process. That is, the way of transferring the pollen through insects and animals. 10\% of pollination takes A-biotic method, which doesn't need any pollinators. Through Wind and diffusion help pollination of such flowering plants and a good example of A-biotic pollination is Grass. A good example of pollinator is Honey bees, and they have also developed the so-called flower constancy. These pollinators tend to visit exclusively only certain flower species and bypass other flower species. Such type of flower reliability may have evolutionary advantages because this will maximize the transfer of flower pollen .Such type of flower constancy may be advantageous for pollinators also, because they will be sure that nectar supply is available with their some degree of memory and minimum cost of learning, switching or exploring. Rather than focusing on some random, but potentially more satisfying on new flower species, and flower dependability may require minimum investment cost and more likely definite intake of nectar. In the world of flowering plants, pollination can be achieved by self-pollination or crosspollination. Cross-pollination means the pollination can occur from pollen of a flower of a different plant, and self-pollination is the fertilization of one flower, such as peach flowers, from pollen of the same flower or different flowers of the same plant, which often occurs when there is no dependable pollinator existing. Biotic, crosspollination may occur at long distance, by the pollinators like bees, bats, birds and flies can fly a long distance. Bees and Birds may behave as Levy flight behaviour, with jump or fly distance steps obeying a Levy allotment. Flower fidelity can be considered as an increment step using the resemblance or difference of two flowers. The biological evolution point of view, the objective of the flower 
pollination is the survival of the fittest and the optimal reproduction of plants in terms of numbers as well as the largely fittest.

Generally the following systems used in Flower Pollination (FP) algorithm,

- System 1. Biotic and cross-pollination has been treated as global pollination process, and pollen-carrying pollinators travel in a way which obeys Levy flights.

- System 2. For local pollination, A- biotic and self-pollination has been utilized.

- System 3. Pollinators such as insects can develop flower reliability, which is equivalent to a reproduction probability and it is proportional to the similarity of two flowers implicated.

- System 4. The communication of local pollination and global pollination can be controlled by a control probability $p \in[0,1]$, with a slight bias towards local pollination.

System 1 and flower reliability can be represented mathematically as

$x_{i}^{t+1}=x_{i}^{t}+\gamma L(\lambda)\left(x_{i}^{t}-g_{*}\right)$

Where $x_{i}^{t}$ is the pollen $i$ or solution vector $x_{i}$ at iteration $t$, and $g_{*}$ is the current best solution found among all solutionsat the current generation/iteration. Here $\gamma$ is a scaling factor to control the step size. $L(\lambda)$ is the parameter that corresponds to the strength of the pollination, which essentially is also the step size. Since insects may move over a long distance with various distance steps, we can use a Levy flight to mimic this characteristic efficiently. We draw $L>0$ from a Levy distribution

$L \sim \frac{\lambda \Gamma(\lambda \sin (\Pi \lambda / 2))}{\Pi} \frac{1}{s^{1+\lambda}},\left(s \gg s_{0}>0\right)$

Here, $\Gamma(\lambda)$ is the standard gamma function, and this distribution is valid for large steps $s>0$.

Then, to model the local pollination, for both system 2 and system 3 can be represented as

$x_{i}^{t+1}=x_{i}^{t}+\in\left(x_{j}^{t}-x_{k}^{t}\right)$

Where $x_{j}^{t}$ and $x_{k}^{t}$ are pollen from different flowers of the same plant species. This essentially mimics the flower reliability in a limited neighbourhood. Mathematically, if $x_{j}^{t}$ and $x_{k}^{t}$ comes from the same species or selected from thesame population, this equivalently becomes a local random walk if we draw $\in$ from a uniform distribution in [0,1].Though Flower pollination performance can occur at all balance, local and global, neighbouring flower patch or flowers in the not-so-far-away neighbourhood are more likely to be pollinated by local flower pollen than those far away. In order to mimic this, we can effectively use a control probability (system 4) or proximity probability $p$ to switch between common global pollination to intensive local pollination. To start with, we can use a raw value of $p=0.8$ as an initially value. The simplest method is to use a weighted sum to combine all multiple objectives into a composite single objective as follows,

$f=\sum_{i=1}^{m} w_{i} f_{i} \sum_{i=1}^{m} w_{i}=1, w_{i}>0$ 
Where $m$ is the number of objectives and $\mathrm{w}_{\mathrm{i}}(\mathrm{i}=1, \ldots, \mathrm{m})$ are non-negative weights.

FP Algorithm for solving optimal reactive power optimization

Step 1.Objective min of $(\mathrm{x}), \mathrm{x}=\left(\mathrm{x}_{1}, \mathrm{x}_{2}, \ldots, \mathrm{x}_{\mathrm{d}}\right)$

Step 2.Initialize a population of $n$ flowers

Step 3.Find the best solution $g_{*}$ in the initial population

Step 4. Define a control probability $p \in[0,1]$

Step5. Define a stopping criterion (a fixed number of generations/iterations)

Step6. While ( $\mathrm{t}<$ MaxGeneration)

Step6. For $\mathrm{i}=1: \mathrm{n}$ (all $\mathrm{n}$ flowers in the population)

Step7. If rand $<p$,

Step8. Draw a (d-dimensional) step vector L which obeys Levy distribution Global pollination throughx $\mathrm{i}_{\mathrm{i}}^{\mathrm{t}+1}=\mathrm{x}_{\mathrm{i}}^{\mathrm{t}}+\mathrm{L}\left(\mathrm{x}_{\mathrm{i}}^{\mathrm{t}}-\mathrm{g}_{*}\right)$

Else

step9. Draw $\in$ from a uniform distribution in $[0,1]$

Step 10.Do local pollination through $\mathrm{x}_{\mathrm{i}}^{\mathrm{t}+1}=\mathrm{x}_{\mathrm{i}}^{\mathrm{t}}+\in\left(\mathrm{x}_{\mathrm{j}}^{\mathrm{t}}-\mathrm{x}_{\mathrm{k}}^{\mathrm{t}}\right)$

End if

step10. Evaluate new solutions

step11. If new solutions are better, update them in the population

End for

step12. Find the current best solution $\mathrm{g}_{*}$

End while

Output - best solution has been found

\section{Simulation Results}

At first Flower Pollination (FP) algorithm has been tested in standard IEEE-57 bus power system. The reactive power compensation buses are 18, 25 and 53. Bus 2, 3, 6, 8, 9 and 12 are PV buses and bus 1 is selected as slack-bus. The system variable limits are given in Table 1.

The preliminary conditions for the IEEE-57 bus power system are given as follows:

$\mathrm{P}_{\text {load }}=12.130$ p.u. Q $_{\text {load }}=3.050$ p.u.

The total initial generations and power losses are obtained as follows:

$\sum P_{G}=12.370$ p.u. $\sum Q_{G}=3.3270$ p.u.

$\mathrm{P}_{\text {loss }}=0.25621$ p.u. $\mathrm{Q}_{\text {loss }}=-1.2100$ p.u.

Table 2 shows the various system control variables i.e. generator bus voltages, shunt capacitances and transformer tap settings obtained after optimization which are within the acceptable limits. In Table 3, shows the comparison of optimum results obtained from proposed methods with other optimization techniques. These results indicate the robustness of proposed approaches for providing better optimal solution in case of IEEE-57 bus system.

Table 1: Variable Limits

\begin{tabular}{|l|l|l|l|l|l|l|l|}
\hline \multicolumn{7}{|l|}{ Reactive Power Generation Limits } \\
\hline Bus no & 1 & 2 & 3 & 6 & 8 & 9 & 12 \\
\hline Qgmin & -1.4 & -.015 & -.02 & -0.04 & -1.3 & -0.03 & -0.4 \\
\hline Qgmax & 1 & 0.3 & 0.4 & 0.21 & 1 & 0.04 & 1.50 \\
\hline
\end{tabular}




\begin{tabular}{|c|c|c|c|c|c|}
\hline \multicolumn{6}{|c|}{ Voltage And Tap Setting Limits } \\
\hline vgmin & Vgmax & vpqmin & Vpqmax & tkmin & tkmax \\
\hline 0.9 & 1.0 & 0.91 & 1.05 & 0.9 & 1.0 \\
\hline \multicolumn{4}{|c|}{ Shunt Capacitor Limits } & & \\
\hline Bus no & 18 & 25 & 53 & & \\
\hline Qcmin & 0 & 0 & 0 & & \\
\hline Qcmax & 10 & 5.2 & 6.1 & & \\
\hline
\end{tabular}

Table 2: Control variables obtained after optimization

\begin{tabular}{|l|l|}
\hline Control Variables & FP \\
\hline V1 & 1.10 \\
\hline V2 & 1.021 \\
\hline V3 & 1.020 \\
\hline V6 & 1.022 \\
\hline V8 & 1.020 \\
\hline V9 & 1.000 \\
\hline V12 & 1.000 \\
\hline Qc18 & 0.0501 \\
\hline Qc25 & 0.192 \\
\hline Qc53 & 0.0241 \\
\hline T4-18 & 1.000 \\
\hline T21-20 & 1.030 \\
\hline T24-25 & 0.710 \\
\hline T24-26 & 0.720 \\
\hline T7-29 & 1.031 \\
\hline T34-32 & 0.741 \\
\hline T11-41 & 1.002 \\
\hline T15-45 & 1.021 \\
\hline T14-46 & 0.890 \\
\hline T10-51 & 1.000 \\
\hline T13-49 & 1.030 \\
\hline T11-43 & 0.900 \\
\hline T40-56 & 0.900 \\
\hline T39-57 & 0.950 \\
\hline T9-55 & 0.950 \\
\hline & \\
\hline
\end{tabular}

Table 3: Comparison results

\begin{tabular}{|l|l|l|l|l|}
\hline S.No. & Optimization Algorithm & Finest Solution & Poorest Solution & Normal Solution \\
\hline 1 & NLP [38] & 0.25902 & 0.30854 & 0.27858 \\
\hline 2 & CGA [38] & 0.25244 & 0.27507 & 0.26293 \\
\hline 3 & AGA [38] & 0.24564 & 0.26671 & 0.25127 \\
\hline 4 & PSO-w [38] & 0.24270 & 0.26152 & 0.24725 \\
\hline 5 & PSO-cf [38] & 0.24280 & 0.26032 & 0.24698 \\
\hline 6 & CLPSO [38] & 0.24515 & 0.24780 & 0.24673 \\
\hline 7 & SPSO-07 [38] & 0.24430 & 0.25457 & 0.24752 \\
\hline
\end{tabular}




\begin{tabular}{|l|l|l|l|l|}
\hline 8 & L-DE [38] & 0.27812 & 0.41909 & 0.33177 \\
\hline 9 & L-SACP-DE [38] & 0.27915 & 0.36978 & 0.31032 \\
\hline 10 & L-SaDE [38] & 0.24267 & 0.24391 & 0.24311 \\
\hline 11 & SOA [38] & 0.24265 & 0.24280 & 0.24270 \\
\hline 12 & LM [39] & 0.2484 & 0.2922 & 0.2641 \\
\hline 13 & MBEP1 [39] & 0.2474 & 0.2848 & 0.2643 \\
\hline 14 & MBEP2 [39] & 0.2482 & 0.283 & 0.2592 \\
\hline 15 & BES100 [39] & 0.2438 & 0.263 & 0.2541 \\
\hline 16 & BES200 [39] & 0.3417 & 0.2486 & 0.2443 \\
\hline 17 & Proposed FP & 0.22018 & 0.23052 & 0.22174 \\
\hline
\end{tabular}

\section{Conclusion}

In this Flower pollination (FP) algorithm successfully solved optimal reactive power h problem by considering various constraints. The biological evolution point of view, the objective of the flower pollination is the survival of the fittest and the optimal reproduction of plants in terms of numbers as well as the largely fittest. In order to evaluate the performance of the proposed Flower Pollination (FP) algorithm, it has been tested on IEEE 57 bus system and compared to other standard reported algorithms. Simulation results show that FP algorithm is better than other algorithms in reducing the real power loss and voltage profiles are within the limits.

\section{References}

[1] O.Alsac, and B. Scott, "Optimal load flow with steady state security”, IEEE Transaction. PAS 1973, pp. 745-751.

[2] Lee K Y ,Paru Y M , Oritz J L -A united approach to optimal real and reactive power dispatch , IEEE Transactions on power Apparatus and systems 1985: PAS-104 : 1147-1153

[3] A.Monticelli , M .V.F Pereira, and S. Granville, "Security constrained optimal power flow with post contingency corrective rescheduling", IEEE Transactions on Power Systems :PWRS-2, No. 1, pp.175-182.,1987.

[4] DeebN, Shahidehpur S.M, Linear reactive power optimization in a large power network using the decomposition approach. IEEE Transactions on power system 1990: 5(2) : 428-435

[5] E. Hobson ,'Network consrained reactive power control using linear programming, ' IEEE Transactions on power systems PAS -99 (4) ,pp 868=877, 1980

[6] K.Y Lee, Y.M Park, and J.L Oritz, "Fuel -cost optimization for both real and reactive power dispatches", IEE Proc; 131C,(3), pp.85-93.

[7] M.K. Mangoli, and K.Y. Lee, "Optimal real and reactive power control using linear programming", Electr.PowerSyst.Res, Vol.26, pp.1-10, 1993.

[8] C.A. Canizares, A.C.Z.de Souza and V.H. Quintana, "Comparison of performance indices for detection of proximity to voltage collapse," vol. 11. no.3, pp.1441-1450, Aug 1996.

[9] S.R.Paranjothi, andK.Anburaja, "Optimal power flow using refined genetic algorithm", Electr.PowerCompon.Syst, Vol. 30, 1055-1063, 2002.

[10] D. Devaraj, and B. Yeganarayana, "Genetic algorithm based optimal power flow for security enhancement”, IEE proc-Generation.Transmission and. Distribution; 152, 6 November 2005.

[11] Berizzi, C. Bovo, M. Merlo, and M. Delfanti, "A ga approach to compare orpf objective functions including secondary voltage regulation,” Electric Power Systems Research, vol. 84, no. 1, pp. 187 - 194, 2012. 
[12] C.-F. Yang, G. G. Lai, C.-H. Lee, C.-T. Su, and G. W. Chang, "Optimal setting of reactive compensation devices with an improved voltage stability index for voltage stability enhancement," International Journal of Electrical Power and Energy Systems, vol. 37, no. 1, pp. $50-57,2012$.

[13] P. Roy, S. Ghoshal, and S. Thakur, "Optimal var control for improvements in voltage profiles and for real power loss minimization using biogeography based optimization," International Journal of Electrical Power and Energy Systems, vol. 43, no. 1, pp. 830 - 838, 2012.

[14] B. Venkatesh, G. Sadasivam, and M. Khan, "A new optimal reactive power scheduling method for loss minimization and voltage stability margin maximization using successive multi-objective fuzzy lp technique," IEEE Transactions on Power Systems, vol. 15, no. 2, pp. 844 - 851, may 2000.

[15] W. Yan, S. Lu, and D. Yu, "A novel optimal reactive power dispatch method based on an improved hybrid evolutionary programming technique," IEEE Transactions on Power Systems, vol. 19, no. 2, pp. 913 - 918, may 2004.

[16] W. Yan, F. Liu, C. Chung, and K. Wong, "A hybrid genetic algorithminterior point method for optimal reactive power flow," IEEE Transactions on Power Systems, vol. 21, no. 3, pp. 1163 1169, aug. 2006.

[17] J. Yu, W. Yan, W. Li, C. Chung, and K. Wong, "An unfixed piecewiseoptimal reactive powerflow model and its algorithm for ac-dc systems," IEEE Transactions on Power Systems, vol. 23, no. 1 , pp. $170-176$, feb. 2008.

[18] F. Capitanescu, "Assessing reactive power reserves with respect to operating constraints and voltage stability," IEEE Transactions on Power Systems, vol. 26, no. 4, pp. 2224-2234, nov. 2011.

[19] Z. Hu, X. Wang, and G. Taylor, "Stochastic optimal reactive power dispatch: Formulation and solution method," International Journal of Electrical Power and Energy Systems, vol. 32, no. 6, pp. $615-621,2010$.

[20] Kargarian, M. Raoofat, and M. Mohammadi, "Probabilistic reactive power procurement in hybrid electricity markets with uncertain loads," Electric Power Systems Research, vol. 82, no. 1, pp. 68 $-80,2012$.

[21] D. Karaboga, “An idea based on honey bee swarm for numerical optimization,” Tech. Rep. TR06, Erciyes Univ. Press, Erciyes, 2005.

[22] D. Karaboga and B. Basturk, "A powerful and efficient algorithm fornumerical function optimization: Artificial bee colony(ABC)algorithm," Journal of Global Optimization , Vol. 39, No. 3, pp. 459-471, 2007.

[23] D. Karaboga and B. Basturk, "On the performance of artificial beecolony (ABC) algorithm," Applied Soft computing, Vol. 8, pp. 687-697, 2008.

[24] D. Karaboga and B. Akay, "A comparative study of artificial Beecolony algorithm," Applied Mathematics and Computation, Vol. 214,No. 1, pp. 108-132, 2009.

[25] D. Whitley, “A genetic Algorithm tutorial," Statistics and Computing, Vol. 4, pp. 65-85, 1994.

[26] D. Karaboga and B. Akay, "An artificial bee colony (abc) algorithm ontraining artificial neural network 15th IEEE Signal Processing andCommunications Applications, pp.1-4, 2007.

[27] S. K. Udgata, S. L. Sabat and S. Mini, "Sensor deployment in irregularterrain using artificial bee colony algorithm," IEEE Congress on Nature\& Biologically Inspired Computing, pp. 1309-1314, 2009.

[28] B. Akay and D. Karaboga, "Artificial bee colony algorithm for largescaleproblems and engineering design optimization," Journal ofIntelligent Manufacturing, Vol. 23, No. 4, pp. 10011014, 2010.

[29] B. Alatas, "Chaotic bee colony algorithm for global numericaloptimization," Expert Systems with Applications, Vol. 37, pp. 5682-5687, 2010.

[30] G. Zhu and S. Kwong, "Gbest-guided artificial bee colony algorithm fornumerical function optimization,” Applied Mathematics andComputation, Vol. 217, pp. 3166-3173, 2010. 
[31] A. Banharnsakun, T. Achalakul and B. Sirinaovakul, "The best-so-farselection in artificial bee colony algorithm,” Applied Soft Computing,Vol. 11, No. 2, pp. 2888-2901, 2011.

[32] D. Karaboga and B. Gorkemli, "A combinatorial artificial bee colonyalgorithm for traveling salesman problem," International Symposium onInnovation in Intelligent Systems and Applications (INISTA), pp. 50-53, 2011.

[33] W. Gao and S. Liu, "A modified artificial bee colony algorithm, "Computers \& Operations Research, Vol. 39. pp. 687-697, 2012.

[34] Yang, X. S. (2012), Flower pollination algorithm for global optimization, in: Unconventional Computation and Natural Computation, LectureNotes in Computer Science, Vol. 7445, pp. 240249.

[35] Oily Fossils provide clues to the evolution of flowers, ScienceDaily,5April2001.http://www.sciencedaily.com/releases/2001/04/010403071438.htm

[36] Glover, B. J., (2007). Understanding Flowers and Flowering: An Integrated Approach, Oxford University Press, Oxford, UK.

[37] Waser, N.M., Flower constancy: definition, cause and measurement. The American Naturalist, 127(5), 1986, pp. 596-603.

[38] Chaohua Dai, Weirong Chen, Yunfang Zhu, and Xuexia Zhang, "Seeker optimization algorithm for optimal reactive power dispatch," IEEE Trans. Power Systems, Vol. 24, No. 3, August 2009, pp. 1218-1231.

[39] J. R. Gomes and 0. R. Saavedra, "Optimal reactive power dispatch using evolutionary computation: Extended algorithms," IEE Proc.-Gener. Transm. Distrib.. Vol. 146, No. 6. Nov. 1999.

*Corresponding author.

E-mail address: gklenin@ gmail.com 